\title{
How People Disclose Themselves Differently According To The Strength Of Relationship In SNS?
}

Bitna Kim, Ewha Womans University, South Korea

Kyung-Shik Shin, Ph.D., Ewha Womans University, South Korea

Sangmi Chai, Ph.D., Ewha Womans University, South Korea

\begin{abstract}
Self-disclosure is defined as "act of revealing personal information to others" (Archer, 1980, p.183). It plays a key role in development and maintenance of relationships.

Since many companies adopt social networking services for their organizational information sharing platform, it is important to identify the process of creating and maintaining social relationship in virtual spaces for successful adoption of SNS. In this research, we identify a selfdisclosure as a driving factor for initiating and maintaining online social relationships.
\end{abstract}

This research assumes that the self-disclose strategy adopted by participants in a communication process would be very similar between a face to face communication and a communication through SNS. In addition, this study explores that how the strength of social relationship does affects participants' self-discloser strategy in SNS.

Self-disclosure on SNS is multidimensional and it consists of five dimensions; intent to disclose, amount, the positive-negative nature, the honesty-accuracy, and general depth-control of disclosure.

Our research indicates that strength of relationship affect negatively the amount of disclosure on SNS. SNS users, in other words, less reveal themselves in terms of both frequency and duration to other user in strong tie than in weak tie. We found that strength of social ties significantly influenced dimensions of self-disclosure except for the positive-negative nature of disclosure.

Keywords: SNS, Self-Disclosure; Strength of Relationship; Online Communications

\section{INTRODUCTION}

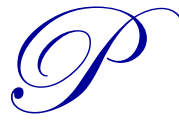

eople live in society having various relationships. They meet other people, share and express their feelings and thoughts with them. A relation can be formed and maintained by people through interactive communication process. Fast developing Information Technologies enable people can extend their relationship in virtual society. Recently individuals are establishing relationships through Online Social Networking Services (SNS) such as Facebook, Google+, and Twitter. These SNS provide various functions people can exchange information such as personal profile, files and pictures with others. While they sharing their idea, thoughts and information, they construct their social network in cyber space likes that of offline society. Selfdisclosing behaviors in the communication process has been identified as a core factor to initiate and maintain social relationship (Archer 1980; Greene et al. 2006; Lynn 1978).

Self-disclosure is defined as "act of revealing personal information to others" (Archer 1980, p.183). According to previous research, self-disclosing process has a reciprocal characteristic so that one's disclosure 
encourages a partner's self-disclose. This reciprocal process of self-disclosure causes increased knowledge and information about each other and contributes to develop a relationship (Greene et al. 2006). When an individual discloses himself or herself, a partner in the relationship feels obligations to exchange comparable information so that the partner tend to behave to maintain an equality position in a relationship. Exchange of self-disclosing information could help for relationship participants to attain equal position in a relationship. Inequality in a relationship is considered as a one of causes reduce participations in the relationship. As inequality creates tension and uncertainty of the relationship, it stimulates participants' disclosures with intention to reduce inequality (Lynn 1978).

Since many companies adopt SNS for their organizational information sharing platform, it is important to identify the process of creating and maintaining social relationship in virtual spaces for successful adoption of SNS. In this research, we identify a self-disclosure as a driving factor for creating and maintaining online social relationships. The objectives of this research are in two folds: First, to explorer the users' self-disclosures on SNS based on the dimensions of self-disclosure theory (Wheeless and Grotz 1976) and Second, to discover the difference in each dimension according to strength of relationship.

Recently it is very critical for firms to collect customers' personal information to deliver personalized communication message as well as to provide customized products and services. For that reason, companies spend a lot of efforts to collects personal information from various websites. However consumers are reluctant to share their personal information when they aware companies' intention. In SNS context, many users share tremendous personal information include pictures, opinions, emotions and locations where they are. If firms can understand the users' spontaneous behavior to share personal information in SNS community, they can do more efficient communication with their customers. This study focuses on people's self-disclosure when they maintain social relationship. People voluntarily do self-disclosure as reciprocal behaviors to increased knowledge and information about target partner as well as to develop a relationship. Since there is little research about the role self-disclosure in online setting, this research results could contribute to understanding virtual social relationship in SNS context and personal information sharing behavior in online communities.

\section{LITERATURE REVIEW}

\section{Self-Disclosure}

Self-disclosure is the concept which denotes both a personality construct and an interaction process (Cozby 1973). It is defined as "any information about himself which person A communicates verbally to a person B" (Cozby, 1973, p.73).

There are ample researches about self-discloser in psychology area. Miller and Read (1987) considered self-disclosure to be a strategy in maintain social relationship. They claim that people disclose themselves to attain objectives that are crucial to the individual such as intimacy, impressing others, knowing oneself and desiring attention. These behaviors are essential both to interact and to have relationships with others. Self-disclosure, therefore, plays a crucial role in initiating and maintaining relationships (Greene et al., 2006).

Greene, Derlega and Mathews stated self-disclosure is including any communicative acts which are "all forms of verbal and nonverbal communication reveal something about self" (2006, p.411). They extend the range of self-disclosure from verbal to nonverbal communication. This extension is important because people started to make new way of constructing relationships in virtual social world. Without temporal and spatial limitation, individuals can form their own personality in cyberspace. In addition, they develop social network via nonverbal communicative act such as posting photo, status, and interests.

In the business area, self-disclosers have been receiving more attentions as one of core motivators of consumers to reveal themselves (Andrade et al., 2002; Moon 2003; Lee et al 2008). Today, the competitive business environment enforces firms to provide customized services and products so that it is necessary for them to collect customers' personal information including identifiable information, personal tastes, and interests. As companies use SNS as a core communication channel with their customers, it is critical for them to clearly recognize individual 
customers in SNS community. There are some researches that attempt to investigate the process of self-disclosure in business contexts (Berg \& Derlega, 1987; Lee at al. 2008). When one shares personal information with a conversation partner, the recipient feels the norm of reciprocity in the amount of shared personal information to maintain equal relationship with a conversation partner (Berg \& Derlega, 1987). Another view point of explaining self-disclosure process is the perceived risk relating with personal information sharing (Derlega \& Chaikin, 1977). According to their research, people share personal information only when the shared information will not be used for unintended purposes or they do not expect any harms or risks through sharing behaviors (Derlega \& Chaikin, 1977).

However, in the online like personal SNS websites, people post various personal information regardless norm of reciprocity. More interestingly, they continue to post their personal information even though privacy invasion cases have been showing increasing trend due to SNS so that the risk of sharing personal information is tremendously increased. Since there is few research examining SNS users self-disclosure behaviors, this study could make contributions to academia by providing new knowledge about self-disclosure behaviors in online settings.

\section{DEVELOPMENT OF HYPOTHESIS}

\section{Dimensions of Self-Disclosure}

In this research, we adopted Dimensions of Self-disclosure (Wheeless and Grotz, 1976) and modified them to fit the SNS context. Wheeless and Grotz found that self-disclosure is multidimensional and they discovered five independent dimensions of self-disclosure; intent to disclose, amount of disclosure, the positive-negative nature of disclosure, the honesty-accuracy of disclosure, and general depth-control of disclosure.

Table 1. Dimensions of Self-disclosure (Wheeless and Grotz 1976)

\begin{tabular}{ll}
\hline \multicolumn{1}{c}{ Dimensions } & \multicolumn{1}{c}{ Definition } \\
\hline Intent to disclose & An individual's willingness to make self-revealing disclosure. \\
Amount of disclosure & Both frequency and duration of disclosive messages or message units \\
Positive-Negative Nature of disclosure & Amount of positive or negative information as perceived by the discloser or \\
disclose target. & Honesty or authenticity of disclosure \\
Honesty-Accuracy of disclosure & Self-perceived intimacy of the information-topic revealed \\
\hline
\end{tabular}

First dimension of self-disclosure is intent to disclose. Self-disclosure is an intentional and purposive act (Jourard, 1964; Pearce and Sharp, 1973; Wheeless and Grotz, 1977; Fisher, 1984). Self-disclosure has to be occurred with conscious willingness to make self-revealing disclosure (Wheeless and Grotz, 1977). They state that the discloser as "means to say whatever he or she says" (Fisher, 1984, p.286). Fisher (1984) defines that self-disclosure as the release of ordinarily private information during communication process. In addition, he found that people tend to reveal or discuss personal matter for participants in a close relationship. In this research, we assume that SNS users also have intentions to reveal themselves in online social network. In addition, we argue that users show a different strength of intention to disclose for types of relationships. Thus we assume that there is a difference in willingness to disclose according to strength of social ties. Following hypothesis is stated:

H1: There is a difference in intent to disclose between strong and weak ties.

Second dimension of self-disclosure is amount of disclosure. This dimension includes "both the frequency and the duration of the disclosive messages or message units" (Wheeless and Grotz, 1977, p.342). Although the frequency and the duration of disclosure have classified as separate parameter of self-disclosure in some previous research (Altman and Taylor, 1973; Cozby, 1973), Wheeless and Grotz (1977) found that the frequency and the duration combined into a single factor, general amount of disclosure. Bochner and Burgoon (1982) said people have limited time and energy to having social relations. They, accordingly, focus their resources on few close friends to maintain the relationships. In addition, Calabrese (1975) suggested that anticipated future interaction lead to greater exchange of personal information. Thus, we expect that SNS users provide with different amount of disclosure 
according to strength of social ties. If they anticipate more frequent future interactions with other SNS users then they will share more amount of personal information. Usually, the frequency of interactions is more often for strong ties than weak ties. We, therefore, have following hypothesis:

H2: There is a difference in amount of disclosure between strong and weak ties.

Disclosures may vary in degrees of information of polarity as perceived by discloser or disclose (Wheeless and Grotz, 1976). This is third dimension of self-disclosure; the positive-negative nature of disclosure. Wheeless (1978) found that the people disclose themselves positively rather than negatively. Moreover, positive selfattributions have been found to be increased in self-disclosure for close friend then for strangers because friends have higher commitment to sustaining the relationship (Derlega et al., 1987). Thus, we expect that SNS users' the positive-negative nature of disclosure would be different pursuant to strength of social ties. The difference leads to following hypothesis:

H3: There is a difference in the positive-negative nature of disclosure between strong and weak ties.

Fourth dimension of self-disclosure is the honesty-accuracy of disclosure. Honest disclosure is not necessarily true. A disclosure is considered to be honest if a discloser has a "sincere attempt" to convey what s/he knows to the target (Pearce and Sharp, 1973). Rubin (1975) found that people tend to more honest to stranger because they could "unburden themselves of private thoughts and feelings with relative impunity" (Rubin, 1975, p.256). Likewise, according to strength of social ties, SNS users could have different degrees of burden of having honesty and accuracy of self-disclosure. Thus, we have following hypothesis:

H4: There is a difference in the honesty-accuracy of disclosure between strong and weak ties.

The last dimension of disclosure is general depth-control of disclosure. Depth refers to self-perceived intimacy of information topic disclosed (Altman and Taylor, 1973; Cozby 1973; Wheeless and Grotz 1976). There is an inverse relationship between amount and depth of disclosure. That is, individuals disclose less about more intimate topics. (Taylor, 1968; Cozby, 1973). Levinger (1980) suggested that individuals vary in level of intimacy with phase of relationships. Likewise, SNS users change their depth of disclosure with phase of relationships. It leads to following hypothesis:

H5: There is a difference in general depth-control of disclosure between strong and weak ties.

\section{METHODOLOGY}

\section{Participants}

This study used a structural survey method. Before we carry out large scale survey for general SNS users, a pilot study was conducted for ensuring the quality of survey items. To remove survey participants' biases, we distribute paper based survey to participants. For the pilot study, we asked questions for students who are SNS users in two large universities in Seoul, Republic of Korea.

We used students as the subjects of this study because their age range matches that of most users of SNS. Compared with the general population, graduate and undergraduate students are normally heavy users of SNS and they are familiar to it.

\section{Measurement}

Self-disclosure was operationalized with the Self-disclosure Measurement developed by Wheeless and Grotz (1976) and modified them to fit the SNS context. The Likert-type scale asked participants to respond to a questionnaire composed of thirty four questions in relation to self-disclosure $(7=$ strongly agree, $1=$ strongly disagree). They are used for measuring the degree of self-disclosure according to two aspects; strong ties and weak ties. 


\section{Procedures Plan}

A paired sample t-test was conducted to compare the means of respondents' opinion on five dimensions of self-disclosure on SNS (intent to disclose, amount, the positive-negative nature, the honesty-accuracy, and general depth-control of disclosure) according to strength of social ties.

\section{RESULTS}

A paired-samples t-test was conducted to compare the dimensions of self-disclosure according to strength of social ties. The result is presented in Table 2 .

There was a significant difference of in the scores of intent to disclose for strong ties $(\mathrm{M}=4.95, \mathrm{SD}=0.95)$ and weak ties $(\mathrm{M}=3.54, \mathrm{SD}=1.20) ; \mathrm{t}(173)=16.35, \mathrm{p}=0.000$. Our results illustrate that $\mathrm{SNS}$ users have more intention of self-disclosure to people with strong ties than weak ties. Thus, hypothesis 1 is supported.

We also found a significant difference in the scores of amount for strong $(\mathrm{M}=4.28, \mathrm{SD}=0.93)$ and weak ties $(\mathrm{M}=4.57, \mathrm{SD}=0.82) ; \mathrm{t}(173)=-3.97, \mathrm{p}=0.000$. Specifically, our results suggest that SNS users release fewer amounts of disclosures to people with strong ties than weak ties. Hypothesis 2, therefore, is supported.

Social ties, however, were not found to significantly differ on the positive-negative nature; $t(173)=-0.10$, $\mathrm{p}=0.920, \mathrm{MST}=3.85, \mathrm{SDST}=0.79, \mathrm{MWT}=3.85, \mathrm{SDWT}=0.81$. Thus, hypothesis 3 is not supported.

Our result showed that there was a significant difference in the scores of the honesty-accuracy for strong ties $(\mathrm{M}=4.32, \mathrm{SD}=1.15)$ and weak ties $(\mathrm{M}=3.63, \mathrm{SD}=1.23) ; \mathrm{t}(172)=9.20, \mathrm{p}=0.000$. These results indicate that $\mathrm{SNS}$ users' disclosures are more honest and accurate to people with strong ties than weak ties. Hypothesis 4 is supported by the result of our data analysis.

There was a significant difference in the scores of control of general depth for strong ties $(\mathrm{M}=3.74$, $\mathrm{SD}=1.25)$ and weak ties $(\mathrm{M}=2.92, \mathrm{SD}=1.14) ; \mathrm{t}(172)=9.34, \mathrm{p}=0.000$. Our results show that $\mathrm{SNS}$ users have more control of general depth of disclosure to people with strong ties than weak ties. Hypothesis 5 is also supported.

These results suggest that the strength of social ties really does have effect on the dimensions of selfdisclosure except for the positive-negative nature of disclosure. Figure 1 illustrates the averages of the dimensions from our data analysis and its differences between strong ties and weak ties. Among the dimensions, which have statistically significant difference, intent to disclose showed the biggest difference according to social tie, followed by control of depth of disclosure, the honesty-accuracy of disclosure and amount of disclosure.

Table 2. Observed Placement Exam Results

\begin{tabular}{|c|c|c|c|c|c|}
\hline Dimension & Social tie & Mean & SD & $\mathbf{t}$ & df \\
\hline \multirow{2}{*}{ Intent to disclose } & Strong & 4.95 & 0.95 & \multirow{2}{*}{$16.35^{* * *}$} & \multirow{2}{*}{173} \\
\hline & Weak & 3.54 & 1.20 & & \\
\hline \multirow{2}{*}{ Amount of disclosure } & Strong & 4.28 & 0.93 & \multirow{2}{*}{$-3.97 * * *$} & \multirow{2}{*}{173} \\
\hline & Weak & 4.57 & 0.82 & & \\
\hline \multirow{2}{*}{ Positive-negative nature of disclosure } & Strong & 3.85 & 0.79 & \multirow{2}{*}{-0.10} & \multirow[b]{2}{*}{173} \\
\hline & Weak & 3.85 & 0.81 & & \\
\hline \multirow{2}{*}{ Honesty- accuracy of disclosure } & Strong & 4.32 & 1.15 & \multirow{2}{*}{$9.20 * * *$} & \multirow{2}{*}{172} \\
\hline & Weak & 3.63 & 1.23 & & \\
\hline \multirow{2}{*}{$\begin{array}{l}\text { Control of general depth or intimacy of } \\
\text { disclosure }\end{array}$} & Strong & 3.74 & 1.25 & \multirow{2}{*}{$9.34 * * *$} & \multirow{2}{*}{172} \\
\hline & Weak & 2.92 & 1.14 & & \\
\hline
\end{tabular}

\footnotetext{
$* * * \mathbf{p}<\mathbf{0 . 0 0 1}$
} 
Figure 1. The average of Dimensions of Self-disclosure

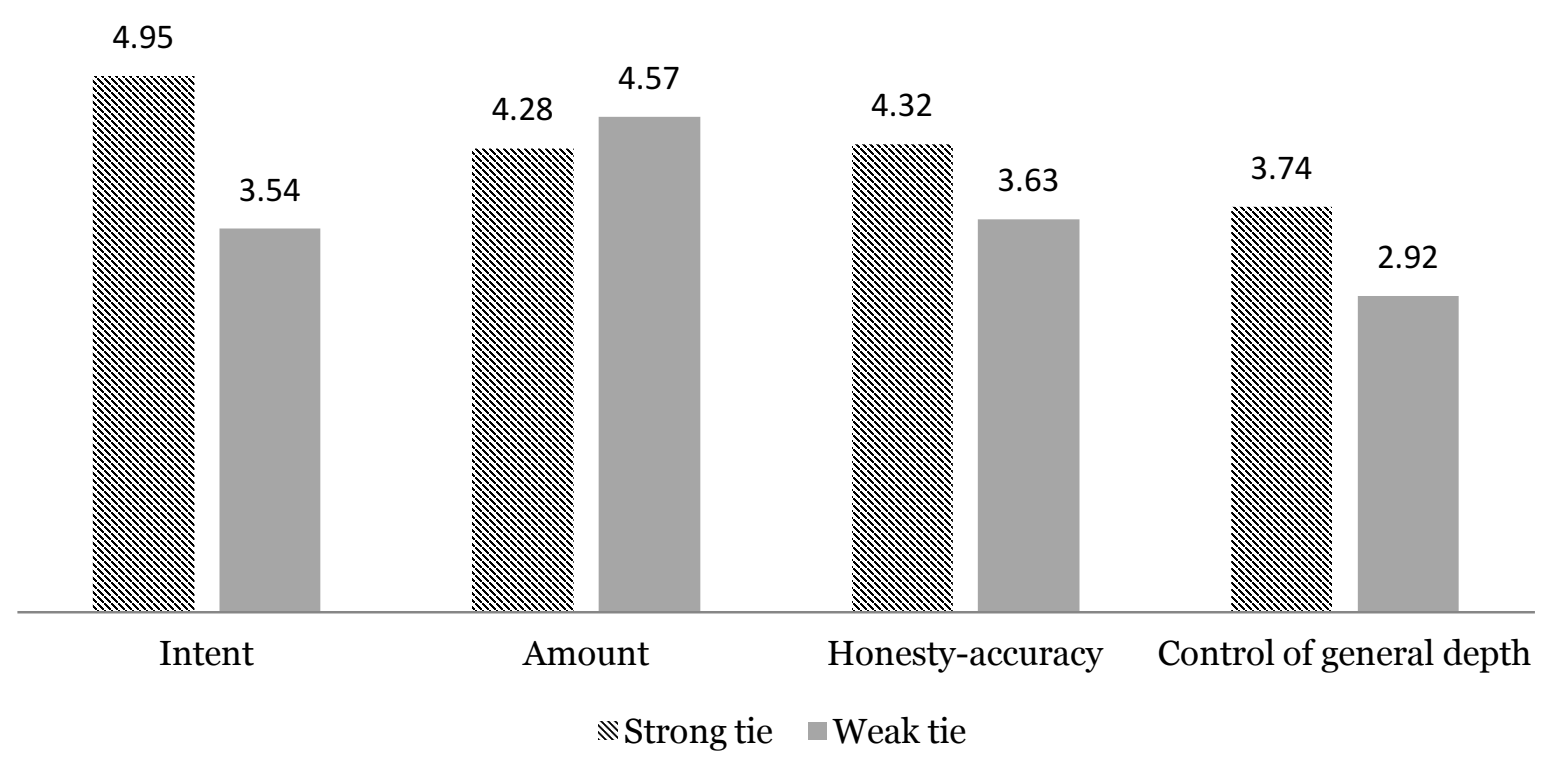

\section{CONCLUSION AND DISCUSSION}

In this research, we explored SNS users' self-disclosure behavior based on self-disclosure theory. In the context of social network services, this study researched how users disclose themselves differently according to strength of relationship. Self-disclosure on SNS is multidimensional and it consists of five dimensions; intent to disclose, amount, the positive-negative nature, the honesty-accuracy, and general depth-control of disclosure. We found that strength of social ties significantly influenced dimensions of self-disclosure except for the positivenegative nature of disclosure.

According to our results, SNS users have more intention to do self-disclosure to other users with strong tie than weak tie. It is showed that users' intent to disclose on SNS is not different from in real life. Fisher (1984) found that people tend to reveal or discuss personal matter for people in a close relationship. Likewise, on SNS which enable users to share personal things, users tend to have more intention to share personal things to other user in a close relationship. Therefore, this research filled a gap in the literatures that users showed same pattern of disclose behavior in SNS like they did in the offline world. More importantly, this research provided empirical evidences users use similar self-discloser strategy to make a relationship in the cyberspace as well as in the real-world at the same way.

Our research indicates that strength of relationship affect negatively the amount of disclosure on SNS. SNS users, in other words, less reveal themselves in terms of both frequency of sharing and duration to other user in strong tie than in weak tie. Probably, it is because users need an additional explanation for their self-disclosure to people in weak ties. An inverse relationship between amount and depth of disclosure is found in previous researches. That is to say, individuals disclose less about more intimate topics (Taylor, 1968; Cozby, 1973). Self-disclosure contains "something about self" (Greene et al., 2006, p. 411) which is a most intimate topic for individuals. Since people in close relationship are already sharing lots of personal information as background knowledge, individual does not have to explain everything. However, with weak ties, individuals call for a long explanation for themselves or their disclosure. Thus, SNS users release more amounts of disclosures to weak ties than strong ties.

This study makes contributions to academic world by empirically examining the strategic use of selfdisclosures in SNS context. Since sharing personal things is one of the efficient ways to initiate relationship with 
others, there are many researches investigating the role of self-disclosers in developing relationship with others in communication field. However, there is little research in virtual settings. Our research brought the research framework in cyberspace to test the role of self-disclosures in evolving relationship in SNS community. Our research findings indicate that SNS users are using similar self- disclosure strategy in online community comparing with that for traditional face to face communication.

Our research provides practical implications. SNS environment is very different with offline face-to face communication setting. In an offline face-to face meeting, shared personal information reaches to limited number of target audience as well as the information could be faded out easily. However, in SNS, shared information is archived and it can be delivered to many number of users in SNS community. Our research findings show that people may not be aware of the difference of two communication settings so that they use similar self-disclosure strategy to develop relationship in online spaces. Since sharing too much personal information would cause various negative consequences like online privacy invasion, SNS users need to control self-disclosers.

However, our research findings reveal that SNS users share more amounts of personal matters with people in weak relationship. This can be explained that people still use traditional communication strategy when they initiate the relationship with others in the cyber space. They have not recognized the environmental difference and keep posting their personal matters in their SNS, leading to drawbacks like privacy invasion. Therefore, SNS service providers need to understand users' communication strategies and tendency and reflect them when service platform design the structural assurance using proper technology to keep users' privacy.

\section{ACKNOWLEDGEMENTS}

This work was supported by the National Research Foundation of Korea Grant funded by the Korean government (NRF-2013S1A3A2054667).

\section{AUTHOR INFORMATION}

Bitna is PhD candidate of Ewha Womans University. She graduated from Ewah School of Business, Ewha Womans Univeristy with M.S in Management. Her concentration is Management Information Systems.

Professor Shin is the head of the Ewha Center for Knowledge and Information Systems. He received a PhD from Korea Advanced Institute of Science and Technology and MBA from the George Washing University. His research interests include decision support systems, virtual collaboration and social network analysis.

Professor Sangmi Chai (corresponding author), is an assistant professor of Ewha Womans University,She received a PhD from SUNY at Buffalo and MBA from Seoul National University. Her research interests include behavioral issues in information systems, information assurance and knowledge management.

\section{REFERENCES}

Altman, I., and Taylor, D.A. (1973). Social Penetration: The Development of Interpersonal Relationships. Holt, Rinehart \& Winston.

Andrade, E. B., Kaltcheva,V., \& Weitz, B. (2002). Self-disclosure on the Web: The impact of privacy policy, reward, and company reputation. Advances in Consumer Research, 29, 350-353.

Archer, R.L. (1980). Self-Disclosure. The self in social psychology, (pp. 183-205).

Berg, J. H., \& Derlega,V. J. (1987). Themes in the study of self-disclosure. In V. J. Derlega \& J. H. Berg (Eds.), Self-disclosure: Theory, research, and therapy (pp. 1-8). New York: Plenum.

Bochner, A.P., and Burgoon, M. (1982). On the Efficacy of Openness in Close Relationships. Communication yearbook (5), (pp. 109-124).

Calabrese, R.J. (1975). The Effects of Privacy and Probability of Future Interaction of Initial Interaction Patterns. Northwestern University.

Cozby, P.C. (1973). Self-Disclosure: A Literature Review. Psychological bulletin (79:2), (pp. 73).

Derlega,V. J.,\& Chaikin, A. L. (1977). Privacy and self-disclosure in social relationships. Journal of Social Issues, 
$33,102-115$.

Derlega, V., Winstead, B.A., Wong, P., and Greenspan, M. (1987). Self-Disclosure and Relationship Development: An Attributional Analysis, Interpersonal Processes: New Directions in Communication Research. Sage Publications, (pp. 172-187).

Fischer, C.S. (1982). To Dwell among Friends: Personal Networks in Town and City. University of Chicago Press.

Fisher, D. (1984). A Conceptual Analysis of Self-Disclosure. Journal for the Theory of Social Behaviour (14:3), (pp. 277-296).

Greene, K., Derlega, V.J., and Mathews, A. (2006). Self-Disclosure in Personal Relationships. The Cambridge handbook of personal relationships, (pp. 409-427).

Jourard, S.M. (1964). The Transparent Self: Self-Disclosure and Well-Being. Van Nostrand Princeton, NJ.

Lee, D.,Im, S, \& Taylor, C.R (2008). Voluntary Self-Disclosure of Information on the Internet: A Multimethod Study of the Motivations and Consequences of Disclosing Information on Blogs, Psychology \& Marketing, Vol. 25(7): 692-710

Levinger, G. (1980). Toward the Analysis of Close Relationships. Journal of Experimental Social Psychology (16:6), (pp. 510-544).

Lynn, S.J. (1978). Three Theories of Self-Disclosure Exchange. Journal of Experimental Social Psychology (14:5), (pp. 466-479).

Pearce, W.B., and Sharp, S.M. (1973). Self-Disclosing Communication. Journal of Communication (23:4), (pp. 409425).

Rubin, Z. (1975). Disclosing Oneself to a Stranger: Reciprocity and Its Limits. Journal of Experimental Social Psychology (11:3), (pp. 233-260).

Taylor, D.A. (1968). The Development of Interpersonal Relationships: Social Penetration Processes. The Journal of Social Psychology (75:1), (pp. 79-90).

Wheeless, L.R., and GROTZ, J. (1976). Conceptualization and Measurement of Reported Self-Disclosure. Human Communication Research (2:4), (pp. 338-346).

Wheeless, L.R., and Grotz, J. (1977). The Measurement of Trust and Its Relationship to Self-Disclosure. Human Communication Research (3:3), (pp. 250-257).

Wheeless, L.R. (1978). A Follow-up Study of the Relationships among Trust, Disclosure, and Interpersonal Solidarity, H000uman Communication Research (4:2), (pp. 143-157). 